\title{
Effects of three cobra venoms on blood coagulation, platelet aggregation, and fibrinolysis
}

\author{
N. MacKAY, J. C. FERGUSON, AND G. P. McNICOL \\ From the University of East Africa, Medical School Extension, Kenyatta National Hospital, Nairobi, Kenya
}

SYNOPSIS The effects of the venoms of Naja melanoleuca, Naja nigricollis, and Ophiophagus hannah on blood coagulation, platelet aggregation, and fibrinolysis were studied in vitro. All three venoms were shown to be anticoagulant. This action appeared to be due to an effect on both the extrinsic ${ }_{\omega}^{N}$ and blood thromboplastin mechanisms. Platelet aggregation in Chandler's tubes and adenosine $\omega^{\omega}$ diphosphate reactivity were inhibited by the three venoms, although in the case of Ophiophagus + hannah venom they were inhibited only with intermediate concentrations. The three venoms 은 possessed proteolytic properties, but when incorporated into purified caseinolytic systems and euglobulin clot lysis systems inhibition of plasmin activity was observed.

The cobra venoms as a group have been considered to be predominantly neurotoxic. In the past the assessment of the effects of these venoms on blood coagulation has been with laboratory techniques which are now largely superseded and frequently the type of cobra venom used has not been specified as mixtures have been used.

This paper reports a detailed study of the effects of three cobra venoms (Naja melanoleuca, Naja nigricollis, and Ophiophagus hannah) on blood coagulation, platelet aggregation, and fibrinolysis, and shows that all three systems are strikingly affected by cobra venoms.

\section{MATERIALS AND METHODS}

VENOM Naja melanoleuca and Naja nigricollis venoms were supplied in desiccator dried form by J. H. Leakey. The dried venom was dissolved in normal saline in a concentration of $10 \mathrm{mg}$ per $\mathrm{ml}$, and dilutions noted in the text are expressed with reference to this concentration. Ophiophagus hannah venom was supplied by J. Ashe. Crude venom, $2.5 \mathrm{ml}$, was diluted in normal saline to a total volume of $25 \mathrm{ml}$, and dilutions are expressed with reference to this final volume.

STREPTOKINASE This was supplied by A. B. Kabi, Stockholm.

THROMBIN Thrombin topical was that supplied by Parke Davis.

hUMAN Plasminogen Grade B was supplied by A. B. Kabi, Stockholm.

Received for publication 27 August 1968.
HUMAN Plasmin This was supplied by A. B. Kabi, Stockholm.

CASEIN SOLUTION This was prepared by the method described by McNicol and Douglas (1964).

ADENOSINE DIPHOSPHATE (ADP) This was supplied by Sigma Chemical Company, St Louis, Mo.

WHOLE BLOOD COAGULATION TIME This was estimated as described by Biggs and Macfarlane (1962), with the modification that $0.1 \mathrm{ml}$ of saline was added to each control, and the effect of $0.1 \mathrm{ml}$ of venom solution was compared with this.

THROMBIN CLOTTING TIME The method used was described by Fletcher, Alkjaersig, and Sherry (1959). Venom, $0.1 \mathrm{ml}$, or in the case of the control experiment, saline, was added to bank plasma and the thrombin clotting time of the mixture determined.

PLASMA RECALCIFICATION TIMES These were determined as described by Biggs and Macfarlane (1962) with the $O$ addition of $0.1 \mathrm{ml}$ saline to the control system and $0.1 \mathrm{~N}$ $\mathrm{ml}$ of various concentrations of venom solution to the $\mathrm{N}$ test system.

THROMBIN-FIBRINOGEN DILUTION CURVE This was cal-ce

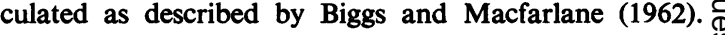

THROMBIN GENERATION TEST The test was as described by Pitney and Dacie (1953). Saline was added to the $\bar{O}$ control system and various concentrations of venom $\mathbb{D}$ were added to the test system.

PROTHROMBIN CONSUMPTION TEST Merskey's (1950) method was used and $0.1 \mathrm{ml}$ saline or venom in saline was added. 
THROMBOPLASTIN GENERATION TEST This was used as described by Biggs and Douglas (1953). To the standard system was added $0.2 \mathrm{ml}$ of saline or venom solution in saline.

DESTRUCTION OF FORMED BLOOD THROMBOPLASTIN To assess this a standard system was allowed to generate blood thromboplastin for five minutes then $0.5 \mathrm{ml}$ venom (or saline) was added and the thromboplastic activity was assessed as in the thromboplastin generation test.

ONE-STAGE 'PROTHROMBIN' TIMES These were calculated as described by Douglas (1962) but $0 \cdot 1 \mathrm{ml}$ of venom or saline was added to the test system.

PLATELET AGgREgation IN THE CHANDLER's TUBE The method used is a modification of that initially described by Chandler (1958). It is essentially a modification of the method of Cunningham, McNicol, and Douglas (1965). In this system, to a solution of $1 \mathrm{ml}$ platelet-rich plasma and $2 \mathrm{ml}$ saline, $0.5 \mathrm{ml}$ of venom solution, or in the case of controls, saline was added. Recalcification was with $1 \mathrm{ml} \mathrm{M} / 10$ calcium chloride. The end point was taken as the 'snowstorm' effect of platelet aggregation.

PLATELET ADP REACTIVITY This was tested by the method of Born and Cross (1963) with the addition of $0.5 \mathrm{ml}$ saline to the control and $0.5 \mathrm{ml}$ venom solution to the test system. Adenosine diphosphate was added to produce a final concentration of $0.5 \mu \mathrm{g} / \mathrm{ml}$.

CASEINOLYTIC ASSAYS These were carried out by the method of Remmert and Cohen (1949) as modified by Alkjaersig (1960). The method is described by McNicol and Douglas (1964) but 0.1 M phosphate buffer $p \mathrm{H} \mathrm{7.6}$ was substituted for acid or alkali. The results are expressed in casein units per $\mathrm{ml}$. Where venom was used $0.5 \mathrm{ml}$ was incorporated in the system in place of an equal volume of phosphate buffer. The stock solutions of Naja melanoleuca and Naja nigricollis were used. In the case of Ophiophagus hannah the stock solution was diluted 1/4 and $0.5 \mathrm{ml}$ of this solution used. Buffer was substituted for streptokinase and plasminogen in those experiments in which these reagents were omitted.

In a further series of experiments plasmin and venom were incubated separately and together, $0.5 \mathrm{ml}$ of plasmin solution and $0.5 \mathrm{ml}$ of venom being used, and $0.1 \mathrm{M}$ phosphate buffer was substituted in equivalent volumes in the series where one constituent was omitted.

EUGLOBULIN CLOT LYSIS TIMES These were measured by the method of Nilsson and Olow (1962). Before adding thrombin to the resuspended euglobulin precipitate $0.1 \mathrm{ml}$ of saline or $\mathbf{0 . 1} \mathrm{ml}$ of varying concentrations of venom in saline were added. Results were expressed in arbitrary units of activity derived from a double logarithmic plot, one unit representing a lysis time of 300 minutes.

\section{RESULTS}

WHOLE BLOOD COAGULATION TIME Results are expressed in Table $I$. It can be seen that adding increasing concentrations of all three venoms leads to progressive lengthening of the clotting times, and in the case of Naja melanoleuca and Naja nigricollis the blood was eventually rendered incoagulable.

PLASMA RECALCIFICATION TIMES Results are expressed in Table II. The venom of Naja nigricollis proved to have the most prominent anticoagulant effect, no clotting taking place when $0.1 \mathrm{ml}$ of a $1 / 1,024$ dilution was incorporated into the system. Ophiophagus hannah venom possessed a weaker though definite anticoagulant action.

THROMBIN GENERATION TEST Results for Naja nigricollis are shown in Figure 1. It will be seen that increasing the concentration of venom in the incubation mixture progressively impaired thrombin

TABLE I

WHOLE BLOOD COAGULATION TIME IN THE PRESENCE OF VENOM ${ }^{1}$ Venom Concentration

\begin{tabular}{|c|c|c|c|c|c|c|}
\hline \multirow[b]{2}{*}{ Venom } & \multirow[b]{2}{*}{ Saline } & \\
\hline & & $1 / 256$ & $1 / 64$ & $1 / 16$ & $1 / 4$ & $1 / 1$ \\
\hline $\begin{array}{l}\text { Naja melanoleuca } \\
\text { Naja nigricollis } \\
\text { Ophiophagus hannah }\end{array}$ & $\begin{array}{l}4 \cdot 25 \\
5 \cdot 75 \\
5 \cdot 50\end{array}$ & $\begin{array}{r}6 \cdot 00 \\
11 \cdot 00 \\
5 \cdot 25\end{array}$ & $\begin{array}{l}6 \cdot 25 \\
\text { Incoagulable } \\
5 \cdot 00\end{array}$ & $\begin{array}{l}9 \cdot 00 \\
\text { Incoagulable } \\
5 \cdot 25\end{array}$ & $\begin{array}{l}\text { Incoagulable } \\
\text { Incoagulable } \\
5 \cdot 50\end{array}$ & $\begin{array}{l}\text { Incoagulable } \\
\text { Incoagulable } \\
12 \cdot 00\end{array}$ \\
\hline
\end{tabular}

TABLE II

PLASMA RECALCIfICATION TIME IN THE PRESENCE OP VENOM ${ }^{1}$

\begin{tabular}{|c|c|c|c|c|c|}
\hline \multirow[b]{2}{*}{ Venom } & \multirow[b]{2}{*}{ Saline } & \multicolumn{4}{|c|}{ Venom Concentration } \\
\hline & & $1 / 16,384$ & $1 / 1,024$ & $1 / 128$ & $1 / 1$ \\
\hline $\begin{array}{l}\text { Naja melanoleuca } \\
\text { Naja nigricollis } \\
\text { Ophiophagus hannah }\end{array}$ & $\begin{array}{r}129 \\
167 \\
97\end{array}$ & $\underline{179}$ & $\begin{array}{r}140 \\
>600 \\
100\end{array}$ & $\begin{array}{r}>600 \\
>600 \\
100\end{array}$ & $\begin{array}{r}>600 \\
>600 \\
370\end{array}$ \\
\hline
\end{tabular}


TABLE III

PROTHROMBIN CONSUMPTION IN THE PRESENCE OF VENOM

\begin{tabular}{|c|c|c|c|c|c|c|}
\hline \multirow[b]{2}{*}{ Venom } & \multirow[b]{2}{*}{ Saline $(\%)$} & \multicolumn{5}{|c|}{ Venom Concentration } \\
\hline & & $1 / 256$ & $1 / 64$ & $1 / 16$ & $1 / 4$ & $1 / 1$ \\
\hline $\begin{array}{l}\text { Naja melanoleuca } \\
\text { Naja nigricollis } \\
\text { Ophiophagus hannah }\end{array}$ & $\begin{array}{l}<5 \\
<5 \\
<5\end{array}$ & $\begin{array}{l}<5 \% \\
92 \% \\
<5 \%\end{array}$ & $\begin{array}{l}26 \% \\
<5 \%\end{array}$ & $\begin{array}{l}100 \% \\
<5 \%\end{array}$ & $19 \%$ & $94 \%$ \\
\hline
\end{tabular}

generation. The other two venoms behaved in a similar manner.

PROTHROMBIN CONSUMPTION Results are expressed in Table III. In all three control systems the prothrombin consumption index was less than $5 \%$. The index exceeded $90 \%$ when $0.1 \mathrm{ml}$ of a $1 / 16$ dilution of the stock solution of Naja melanoleuca was added to the test system. The dilutions of Naja nigricollis and Ophiophagus hannah at which comparable interference with prothrombin consumption took place were $1 / 256$ and $1 / 1$ respectively.

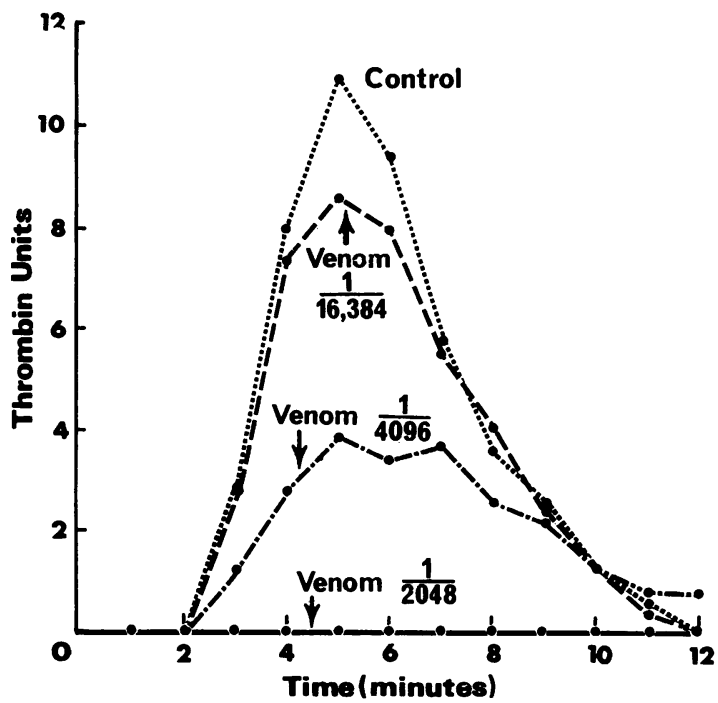

FIG. 1. Effect of various concentrations of the venom of Naja nigricollis on thrombin generation.

THROMBOPLASTIN GENERATION TEST Results for Ophiophagus hannah are illustrated in Figure 2. The three venoms progressively interfered with thromboplastin formation when incorporated into the incubation mixture.

DESTRUCTION OF BLOOD THROMBOPLASTIN The results for Naja melanoleuca are illustrated in Figure 3 . With increasing concentrations of venom added to the incubation mixture there was a progressive decrease in the concentration of thromboplastin $\overrightarrow{-}$ which could be detected.

THROMBIN-FIBRINOGEN REACTION IN THE PRESENCEO OF VENOM Plasma, $0.4 \mathrm{ml}, 0.4 \mathrm{ml}$ platelet suspen sion, and $0.4 \mathrm{ml} \mathrm{M} / 40$ calcium chloride weren

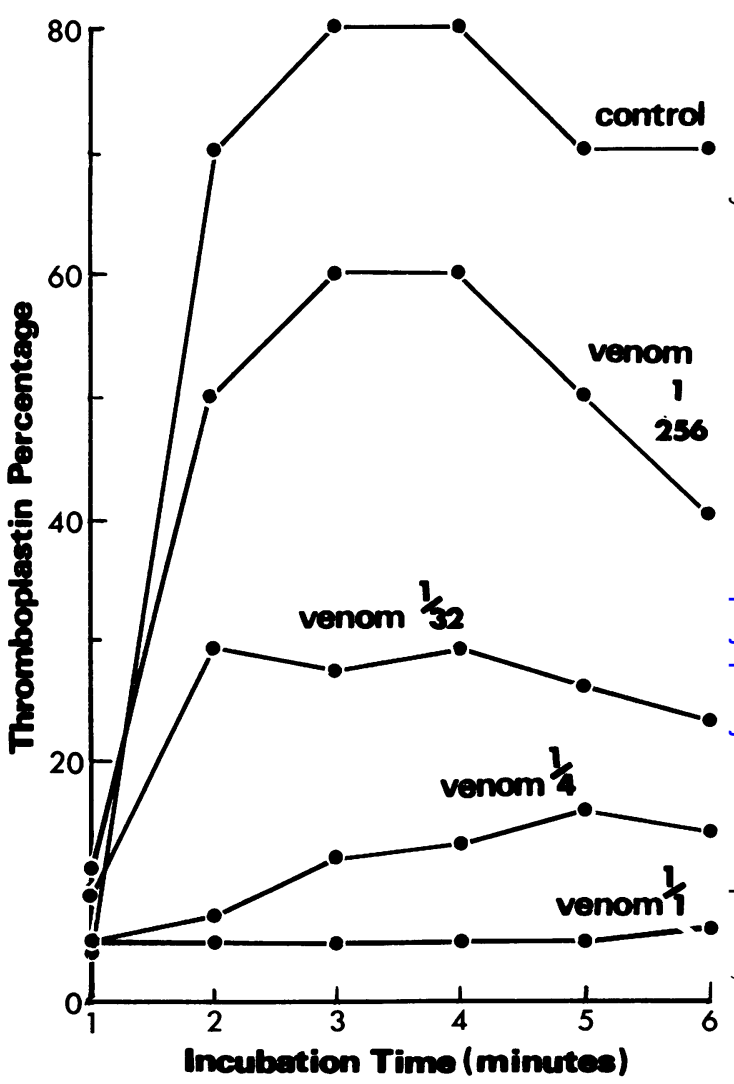

FIG. 2. Effect of various concentrations of the venom of Ophiophagus hannah on thromboplastin generation.

incubated and thrombin was allowed to generate. Aliquots, each of $0.1 \mathrm{ml}$, were removed at one $-\bar{D}$ minute intervals and added together with $0.1 \mathrm{ml}$ of

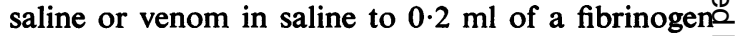
solution. The results for Ophiophagus hannah are shown in Figure 4. No important difference was? 


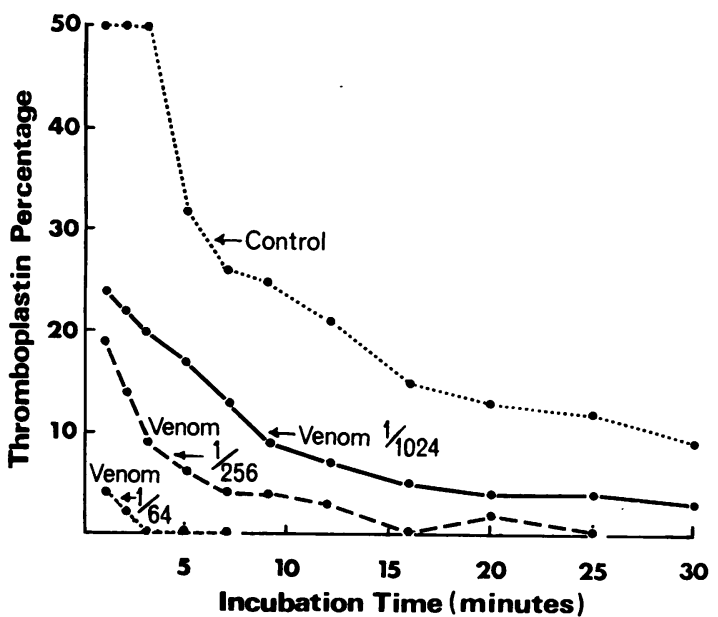

FIG. 3. Effect of various concentrations of the venom of Naja melanoleuca on formed blood thromboplastin.

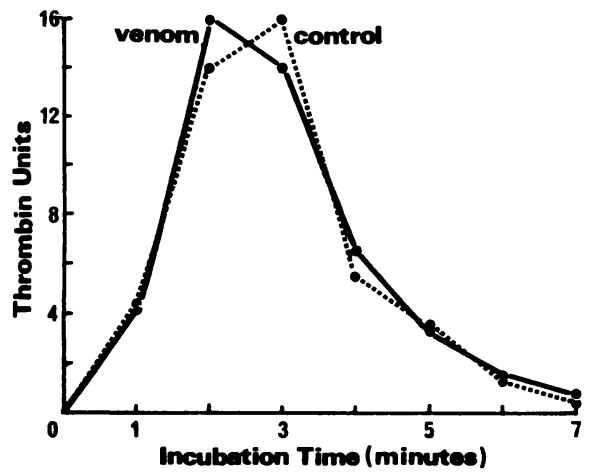

FIG. 4. Effect of Ophiophagus hannah venom on the interaction of thrombin and fibrinogen.

detected, indicating that the venom does not directly interfere with the conversion of fibrinogen to fibrin under the action of thrombin. Similar results were obtained with the venoms of Naja melanoleuca and Naja nigricollis. In all three instances the venoms were used in the concentration of the stock solutions.
ONE-STAGE 'PROTHROMBIN' TIME The results are expressed in Table IV. Naja melanoleuca and Naja nigricollis venoms showed a marked anticoagulant effect. High concentrations of both venoms rendered the test system incoagulable. In the case of Ophiophagus hannah the clotting time was only modestly prolonged.

THROMBIN CLOTTING TIME All three venoms only modestly prolonged the thrombin clotting time of bank plasma. If, however, the venom was incubated with the plasma for one hour at $37^{\circ} \mathrm{C}$ a more prominent anticoagulant effect was observed and this was accentuated when the incubation was continued for 24 hours.

INCUBATION OF VENOM WITH PURIFIED FIBRINOGEN Fifteen $\mathrm{ml}$ of a purified fibrinogen solution $(1 \mathrm{~g}$ per

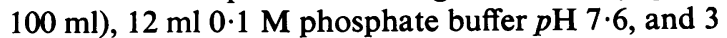
$\mathrm{ml}$ of stock solution of venom in saline were incubated at $37^{\circ} \mathrm{C}$. In the control system saline was substituted for the venom solution. The thrombin clotting time was measured at the beginning of the experiment and at intervals thereafter. At the same time, aliquots, each of $2 \mathrm{ml}$, were removed, the protein was precipitated by adding $2 \mathrm{ml} \mathrm{10 \%}$ trichloracetic acid, and after centrifugation, the tyrosine content of the supernatant was assayed with FolinCiocalteu's reagent. The results are expressed as optical densities using the zero time sample as blank.

The results for Naja melanoleuca are expressed in Figure 5. The other two venoms behaved in a comparable manner.

In the control system the thrombin clotting time did not change significantly during the experiment and there was no evidence of proteolysis as reflected by tyrosine release. When fibrinogen was incubated with the venom, however, the thrombin clotting time was prolonged. At the same time there was a progressive increase in the tyrosine content of the solutions, reflecting the proteolysis of the fibrinogen by the venom.

PLATELET AGGREGATION IN CHANDLER'S TUBE SYSTEM As can be seen from Tables V and VI, the venoms of both Naja melanoleuca and Naja nigricollis inhibit

TABLE IV

ONE-STAGE 'PROTHROMBIN' TIME IN THE PRESENCE OF VENOM ${ }^{1}$

Venom Concentration

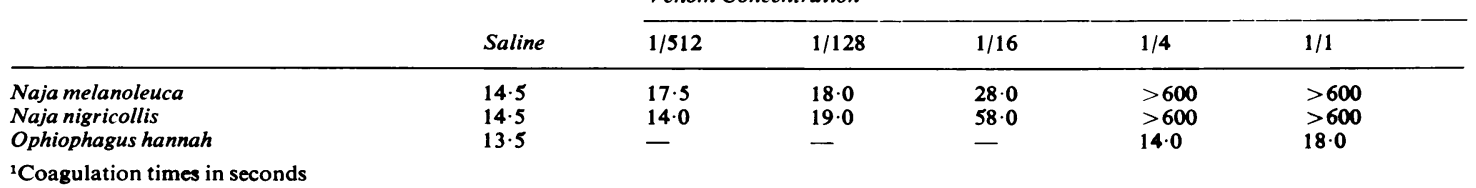




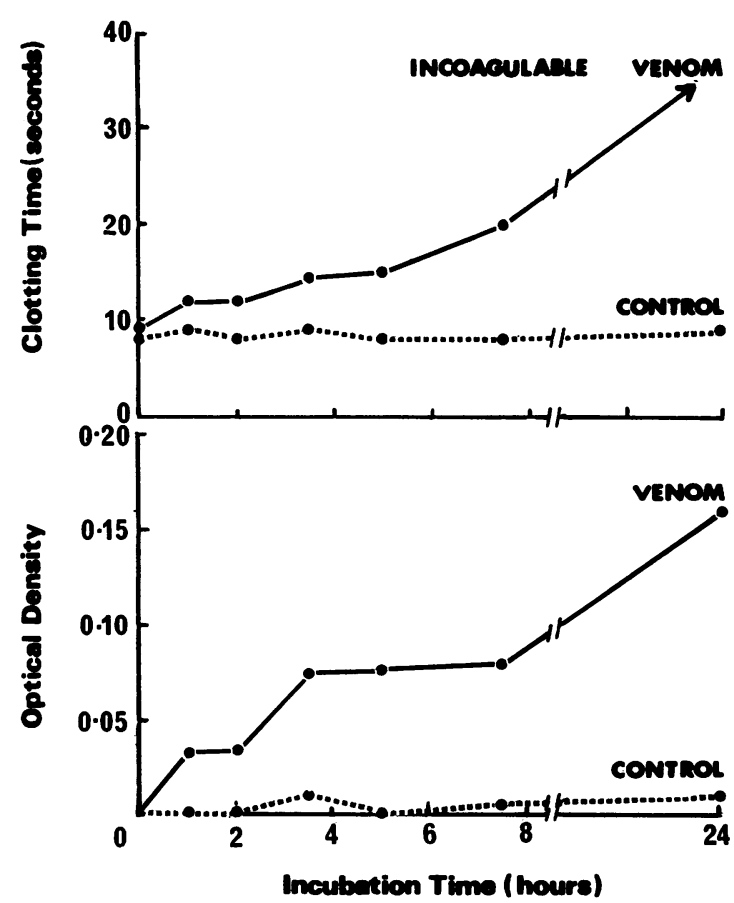

FIG. 5. Effect of the venom of Naja melanoleuca on purified fibrinogen. The upper part of the figure shows the effect of the venom on the thrombin clotting time of the incubation mixture. The lower part demonstrates the fibrinogenolytic effect of the venom.

TABLE V

EFFECT OF VARIOUS CONCENTRATIONS OF Naja melanoleuca AND Naja nigricollis VENOMS ON PLATELET AGGREGATION IN CHANDLER'S TUBES

\begin{tabular}{|c|c|c|c|c|}
\hline & \multicolumn{4}{|c|}{ Delay (sec) of 'Snowstorm' Effect } \\
\hline & \multicolumn{4}{|c|}{ Venom Concentration } \\
\hline & $1 / 10,000$ & $1 / 1,000$ & $1 / 100$ & $1 / 10$ \\
\hline $\begin{array}{l}\text { Iaja melanoleuca } \\
\text { aja nigricollis }\end{array}$ & $\begin{array}{l}\mathbf{0} \\
\mathbf{0}\end{array}$ & $\begin{array}{l}164 \\
251\end{array}$ & $\begin{array}{r}>900 \\
895\end{array}$ & $\begin{array}{l}>900 \\
>900\end{array}$ \\
\hline
\end{tabular}

platelet aggregation. The effect can eventually $b$ diluted out.

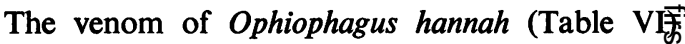
was more interesting because in the strongest concentration available it did not appear to influence platelet aggregation; however, when diluted, delayed platelet aggregation and this effect was not lost until a dilution of $1 / 2,560$ was reached.

PLATELET ADP REACTIVITY Results for Naja melano $\overrightarrow{0}$ leuca are illustrated in Figure 6. All three venomis appeared to inhibit ADP reactivity. Naja melanow leuca venom could, in high concentrations, cons pletely inhibit platelet ADP reactivity. In loweP concentrations the effect was to delay the rate of platelet aggregation in the system and this coulg still be demonstrated at a dilution of 1/100. This effect was least noticeable in the case of Naje nigricollis which even in very high concentrations of $40 \mathrm{mg} / \mathrm{ml}$ only minimally reduced the rate of platelet aggregation.

CASEINOLYTIC ASSAYS The results for Naja nigrio collis are shown in Figure 7. Spontaneous plasminogen activation has been allowed for in all instances The results for each series of experiments represen the mean value plus or minus the standard error of the mean for seven assays performed in duplicate.

All three venoms gave comparable results an $\$$ are directly caseinolytic. Furthermore, the caseinoly $\overrightarrow{\overrightarrow{0}}$ tic activity of streptokinase-activated plasminoge in the presence of venom is less than would be expected from the sum of the activities obtaine $\$$. when the venom is incubated separately from the plasminogen-streptokinase system. These results are statistically significant (Naja melanoleucas $\mathrm{t}=9.2 \mathrm{P}<0.0005 ;$ Naja nigricollis, $\mathrm{t}=8.42 \mathrm{P}<0.0005^{-}$ Ophiophagus hannah, $\mathrm{t}=4.8 \mathrm{P}<0.0025$ ).

Two similar experiments were carried out. In one set of tubes the venom was added to plasminogen before the addition of streptokinase. In the other set the addition of streptokinase preceded that of. venom but no difference was observed in the caseinolytic activities, suggesting that the venoms do not interfere with the activation of plasminoge by streptokinase.

TABLE VI

EFFECT OF VARIOUS CONCENTRATIONS OF Ophiophagus hannah VENOM ON PLATELET AGGREGATION IN CHANDLER'S TUBES Delay (sec) of 'Snowstorm' Effect

\begin{tabular}{|c|c|c|c|c|c|c|c|c|}
\hline \multicolumn{9}{|c|}{ Venom Concentration } \\
\hline $1 / 2,560$ & $1 / 1,280$ & $1 / 640$ & $1 / 320$ & $1 / 160$ & $1 / 80$ & $1 / 40$ & $1 / 20$ & $1 / 10$ \\
\hline 0 & 131 & 241 & 445 & 470 & 204 & 293 & 95 & 0 \\
\hline
\end{tabular}




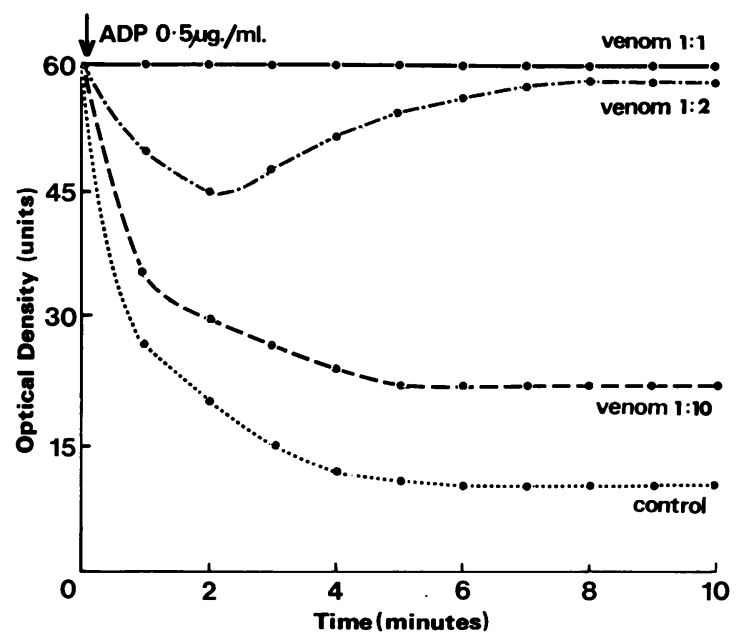

FIG. 6. Effect of the venom of Naja melanoleuca on platelet ADP reactivity.

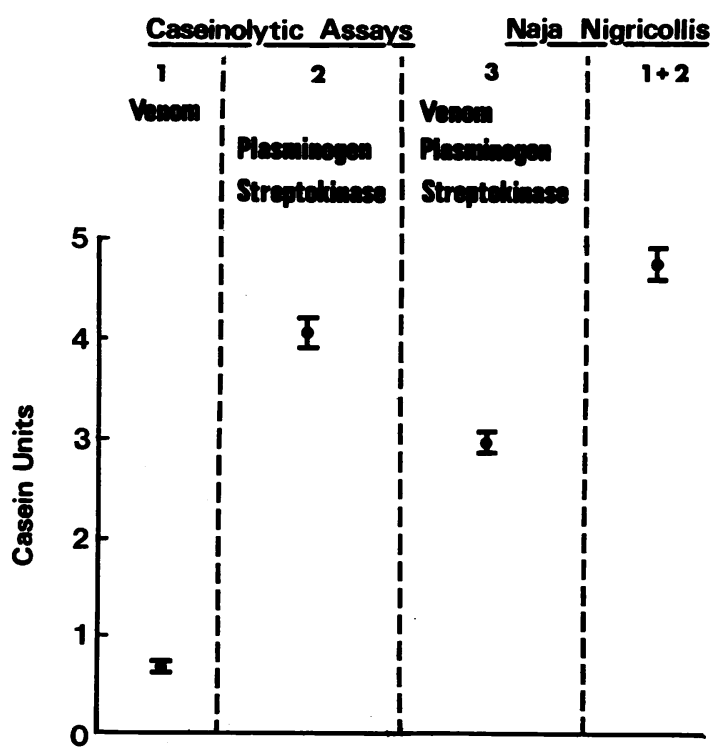

FIG. 7. Effect of the venom of Naja nigricollis on caseinolytic assays incorporating plasminogen and streptokinase. The result in each experiment is the mean and standard error of seven duplicate estimations.
A further experiment was carried out in which purified human plasmin and venoms were incubated separately and together. The results are given in Figure 8. The caseinolytic activities observed when plasmin and venom were incubated together were less than would be expected from the summation of the activities observed on separate incubation. These results are statistically significant (Naja melanoleuca, $\mathrm{t}=4.56 \mathrm{P}<0.0025 ;$ Naja nigricollis, $t=19.44 \quad P<0.0005 ;$ Ophiophagus hannah, $t=15 \cdot 35$ $P<0.0005)$.

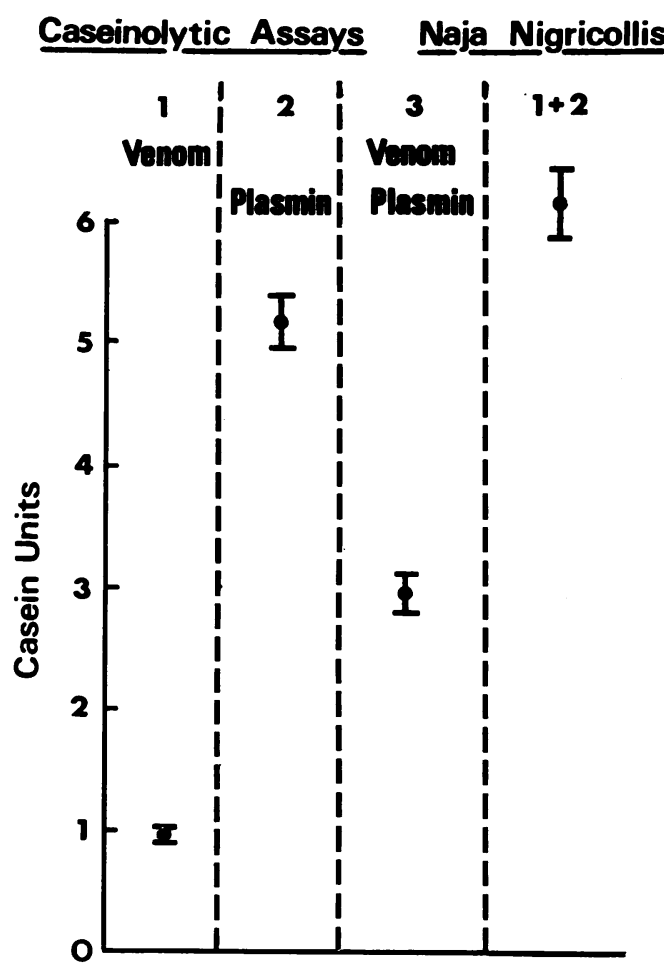

FIG. 8. Effect of venom of Naja nigricollis on caseinolytic assays incorporating purified plasmin. The result in each experiment is the mean and standard error of seven duplicate estimations.

EUGLOBULIN CLOT LYSIS The results are illustrated in Fig. 9 by those for Naja nigricollis. All three venoms in high concentration demonstrate the ability to reduce euglobulin lysis activity.

\section{DISCUSSION}

The three cobra venoms studied have been shown to possess marked anticoagulant properties. The mode of action common to all three was on the intrinsic 
blood thromboplastic mechanism as evidenced by the abnormalities produced in the prothrombin consumption, thromboplastin generation, and the thrombin generation tests. Evidence has been put forward to suggest that these effects are produced by destruction of blood thromboplastin as it is formed, though inhibition of production cannot be excluded as a contributory factor. In addition, the marked prolongation of the one-stage 'prothrombin' time produced by the venoms of Naja melanoleuca and Naja nigricollis is indicative of an action on the extrinsic thromboplastin mechanism. Ophiophagus hannah venom produced only a modest effect on the one-stage 'prothrombin' time though it is possible that with higher concentrations than were used in the current study a more noticeable effect might have been produced.

There was no evidence that the venoms directly interfered with the conversion of fibrinogen to fibrin under the action of thrombin. On incubation the thrombin clotting time was prolonged. This has been shown to be associated with the digestion of fibrinogen, and the defective clotting which results is probably due to breakdown products of fibrinogen interfering with normal fibrin polymerization.

Previous workers have demonstrated that 'cobra venom' is an anticoagulant (Kruse and Dam, 1950). These authors showed that their preparation of venom either inactivated or destroyed thromboplastin. This property could be destroyed by heating the venom. O'Brien (1956), using a mixture of venoms from Naja nigricollis, Naja flava, and Naja hage, showed that cobra venom had an inactivating effect on Christmas factor.

\section{Euglobulin Clot Lysis Naja Nigricollis}

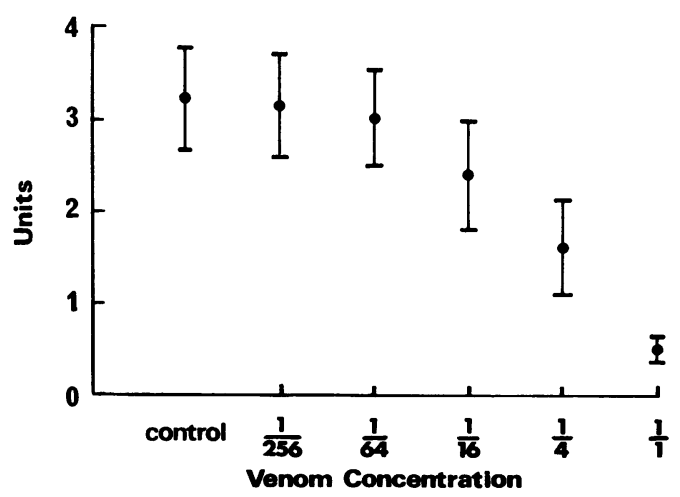

FIG. 9. Effect of various concentrations of Naja nigricollis venom when added to euglobulin clot lysis system. The results in each instance represent the mean and standard error of seven duplicate estimations.
We have been unable to find any previous work on the action of cobra venoms on platelet aggregation and ADP reactivity. The formation of a platelet $\overrightarrow{\bar{s}}$ head is almost certainly of prime importance in the 0 initiation of intravascular clotting. Substances which $\frac{}{0}$ possess the property of preventing or reducing $\frac{\bar{\omega}}{2}$ platelet aggregation might therefore have important $\Phi$ therapeutic applications. Like the mamba venoms (MacKay, Ferguson, and McNicol, 1966), the three ${ }^{\infty}$ cobra venoms studied are capable of inhibiting. platelet aggregation in a Chandler's tube system $\overrightarrow{-}$ and platelet ADP reactivity. The peculiar response obtained with Ophiophagus hannah venom in the Chandler's tube system cannot be effectively explained and is worthy of further study. It may represent two fractions with opposing actions, the effects of which are diluted out at different rates.

The effects of snake venoms on the fibrinolytico mechanism have been poorly studied. Eagle (1937) reported that the venoms of Naja flava and Najaz naja did not digest fibrinogen. In his experiment the venom and fibrinogen were incubated for only one $\vec{\theta}$ hour and this probably explains his inability to demonstrate fibrinogenolysis. It is clearly shown. in the present study that the three venoms produced progressive digestion of fibrinogen as the period of incubation increased and there was parallel pro-o gressive prolongation in the clotting time of the fibrinogen, leading eventually to total failure of $\mathscr{\mathbb { Q }}$ coagulation. The observations confirm the work of $\overrightarrow{\vec{O}}$ Didisheim and Lewis (1956) that crude cobra venom 3 and the venoms of Naja flava and Naja naja are? fibrinogenolytic.

Didisheim and Lewis (1956) also reported the interesting phenomenon that although the cobra?venoms were fibrinogenolytic they showed no 3 fibrinolytic activity when incorporated into blood clots or added to preformed clots. The present study shows that this effect is due to definite antifibrinolytic activity in the venoms tested. This interference ? has been shown to be due to inhibition of the action? of plasmin and not due to interference with the activation of plasminogen. The antifibrinolytic $N$ activity is also seen in the inhibition in euglobulin lysis activity of normal blood by the addition of increasing concentrations of venom, an effect due to $\omega$ antiplasmin but not antiplasminogen activation activity. In these respects the cobra venoms possess similar properties to the venoms of Dendroaspis ${ }_{\infty}$ angusticeps, Dendroaspis polylepis, and Dendroaspis ${ }^{+}$ jamesoni (MacKay, Ferguson, and McNicol, $\frac{T}{0}$ 1968).

Further work is now in progress to establish $\stackrel{\odot}{\odot}$ which of the venom fractions produces the effects $\triangle$ which have been observed and it is also hoped to determine more precisely their mode of action. 
We are grateful to $\mathrm{Mr} \mathrm{J}$. Leakey and $\mathrm{Mr} \mathrm{J}$. Ashe who supplied the venoms. Professor S. Alstead and Professor A. S. Douglas played a major role in establishing laboratory facilities.

Financial assistance was provided by the Kenya Ministry of Health, East African Medical Research Council, Ministry of Overseas Development, Hoechst (East Africa) Ltd, Pfizer Tropical Research Laboratory, Merck, Sharp and Dohme Research Laboratories, The Pfizer Corporation, and ICI Pharmaceutical Division.

Reagents were provided by A.B. Kabi, Stockholm, Sweden.

Requests for reprints to Dr G. P. McNicol, Department of Medicine, Royal Infirmary, Glasgow.

\section{REFERENCES}

Alkjaersig, N. (1960). In NIH Conference on Thrombolytic Agents, edited by H. R. Roberts and J. D. Geraty, p. 316. Chapel Hill.
Biggs, R., and Douglas, A. S. (1953). J. clin. Path., 6, 23. and MacFarlane, R. G. (1962). Human Blood Coagulation and its Disorders, 3rd ed. Blackwell, Oxford.

Born, G. V. R., and Cross, M. J. (1963). Nature (Lond.), 197, 974.

Chandler, A. B. (1958). Lab. Invest., 7, 110.

Cunningham, G. M., McNicol, G. P., and Douglas, A. S. (1965). Lancet, 1, 729.

Didisheim, P., and Lewis, J. H. (1956). Proc. Soc. exp. Biol. (N.Y.), 93, 10.

Douglas, A. S. (1962). Anticoagulant Therapy. Blackwell, Oxford.

Eagle, H. (1937). J. exp. Med., 65, 613.

Fletcher, A. P., Alkjaersig, N., and Sherry, S. (1959). J. clin. Invest., 38, 1096.

Kruse, I., and Dam, H. (1950). Biochim. biophys. Acta. (Amst.), 5, 268.

Mackay, N., Ferguson, J. C., and McNicol, G. P. (1966). E. Afr. med. J., 43, 454.

McNicol and Douglas (1964). Recent Advances in Clinical Pathology, edited by S. C. Dyke, series IV, p. 187. Churchill, London.

Merskey, C. (1950). J. clin. Path., 3, 301.

Nilsson, I. M., and Olow, B. (1962). Acta chir. scand., 123, 247.

O'Brien, J. R. (1956). Brit. J. Haemat., 2, 430.

Pitney, W. R., and Dacie, J. V. (1953). J. clin. Path., 6, 9.

Remmert, L. F., and Cohen, P. P. (1949). J. biol. Chem., 181, 431. 